\title{
Compliance with diphtheria, tetanus, and pertussis immunisation in Bangladesh: factors identifying high risk groups
}

\author{
Sushila Zeitlyn, A K S Mahmudur Rahman, Birthe H Nielsen, Momota Gomes, \\ Poul-Erik Lund Kofoed, Dilip Mahalanabis
}

\begin{abstract}
Objective-To evaluate factors associated with non-compliance with having second vaccination against diphtheria, tetanus, and pertussis in a treatment centre in Dhaka to determine which children were most at risk of not completing immunisation.

Design-Cohort study of infants given first dose of the vaccine and followed up six weeks later to ascertain compliance with having second dose. Factors associated with non-compliance were evaluated.

Setting-Dhaka treatment centre of the International Centre for Diarrhoeal Disease Research, Bangladesh.

Subjects-136 unimmunised children aged 6 weeks to 23 months who lived within reach of the treatment centre. At time of the six week follow up 16 of the children could not be traced and seven had died.
\end{abstract}

Interventions-All children received their first dose of the vaccine. In each case health education workers had informed the mother about the value of immunisation, and she was given clear instructions to bring the child back after four weeks for the second dose.

Main outcome measure-Rate of non-compliance with advice to return child for second vaccination.

Results -46 of 113 children $(41 \%)$ received the second dose of the vaccine. Factors most closely associated with mothers' failure to comply with the second dose were lack of education and low income. Children whose mothers knew most about immunisation at first interview were more likely to have their second dose.

Conclusions-Preventive health care services such as immunisation are appropriately offered in treatment centres, but compliance among children varies with socioeconomic status and mother's education. Further research should be aimed at ways to make health education more effective among uneducated parents.

\section{Introduction}

In 1988 an immunisation programme - the World Health Organisation expanded programme on immunisation-was established in the treatment centre of the International Centre for Diarrhoeal Disease Research, Bangladesh, following WHO guidelines based on concern that immunisation opportunities might be missed in health care facilities.' In 1989 half of the eligible patients had been vaccinated against diphtheria, tetanus, and pertussis before admission to hospital. Parents of children under 2 years who had not completed a course of immunisation were encouraged on discharge to bring their children to the immunisation room, which was open seven days a week from 7 am to $7 \mathrm{pm}$ and where, in 1989,9661 children were seen and vaccinated.

Health workers motivated mothers by means of small group discussion and individual counselling on the wards. Mothers were accompanied by a health worker to the immunisation room, where they received further education about immunisation. Both on the wards and in the immunisation room the workers used visual aids to emphasise the nature of the diseases that vaccination protects against. All patients' mothers or attendants received this information at least once. After vaccination the immunisation schedule was explained and parents informed that their child would need a second dose after four weeks as well as a third and in some cases a fourth visit to complete the immunisation course. They were advised either to go to their nearest immunisation centre or to return to the International Centre for Diarrhoeal Disease Research, Bangladesh, if it was more convenient. The aim of the study was to evaluate the rate of compliance with the advice given about the second dose of diphtheria, tetanus, and pertussis vaccine. The study also aimed at identifying the social and economic characteristics associated with compliance in order to find out which children were most at risk of not completing their immunisation course. In Bangladesh $49 \%$ of 1 year old children were fully immunised with diphtheria, tetanus, and pertussis vaccine in 1988-9. ${ }^{2}$

\section{Subjects and methods}

Patients of the International Centre for Diarrhoeal Disease Research, Bangladesh, aged 6 weeks to 23 months who were unimmunised and brought to the immunisation room were selected by immunisation workers on the basis of residence in one of nine preselected areas within Dhaka city. (These are the areas from which most patients come and which it was feasible to visit.) Workers were instructed to approach eligible patients from the immunisation room in order of their arrival between 830 am and $5 \mathrm{pm}$ for enrolment. Numbers of patients varied but an average of four or five interviews a day were conducted; on some days fewer than four patients who met the inclusion criteria arrived whereas on other days more arrived. In the absence of any invasive procedure refusal to enrol was rare. The selection process took six weeks (May and June 1989).

Initial hospital interview-After immunisation parents or attendants of selected children were interviewed to collect the initial information. Altogether 136 children's parents or attendants were interviewed for information on socioeconomic circumstances. Information on household composition and parents' marital status and educational level was recorded in addition to the child's mid-upper arm circumference and weight for age. Interviewees were asked to evaluate the treatment they had received in hospital and the present state of their child's health. Some basic questions on immunisation knowledge that all parents had been given by the health workers were included. Finally, the interviewer sought the parents' permission to make a home visit after six weeks.

Second interview in community - After six weeks the same interviewer attempted to trace and visit each family for a second interview in their home. During the six weeks seven children had died and 16 had moved and could not be traced. Thus 113 second interviews were conducted. The purpose of the second interview
Correspondence and requests for reprints
Dr Mahalanabis.

BM于 1992;304:606-9 
was to ascertain whether the child had been taken for the second vaccination. Reasons given for follow up or non-follow up were recorded and the parents again asked about their perception of their child's health and the treatment they had received.

Analysis-Data were entered into a microcomputer and validated by visual and logical checks. Descriptive statistics and creation of primary tables were carried out with statistical package for the social sciences PC+ software (SPSS Inc, Chicago, USA). For quantitative variables either a $t$ test or a non-parametric (Wilcoxon's) test was used, as appropriate. Relative risk and $95 \%$ confidence intervals for association between each factor of interest and non-compliance with the second dose of diphtheria, tetanus, and pertussis vaccine were calculated by the method of Greenland and Robins ${ }^{3}$ (with the software EPI INFO, Centers for Disease Control, Atlanta, Georgia, USA). Economic indicators (for example, owning a radio, television, fan, brick house, etc) are highly associated covariates and therefore were evaluated individually. For the study we thought it unnecessary to develop a composite economic indicator. The important point was that the relative risk estimates of individual economic indicators were in the same direction and generally of similar magnitude.

\section{Results}

Of the 113 children whose families were interviewed at six weeks, 67 were boys and 46 girls. Twenty four boys ( $36 \%$ ) and 16 girls (35\%) were firstborn children. The median number of siblings per patient was two with a range of nil to eight. The median educational level of the mothers was one year and of the fathers five years. Although $46(41 \%)$ of the fathers had had no schooling, $31(27 \%)$ had been educated beyond class $\mathrm{X}$. Fifty nine (52\%) of the mothers had not been to school and only two had been educated beyond class X. Only six families $(5 \%)$ had lived for 10 years or more in their present home, and the median length of residence was two years. Ownership of fans, radios, and televisions and type of housing and other facilities such as water

TABLE I-Selected socioeconomic indicators associated with non-compliance with second dose of diphtheria, tetanus, and pertussis vaccine and their relative risks. Except where stated otherwise, figures are numbers of families of children who did or did not receive second dose of vaccine

\begin{tabular}{|c|c|c|c|c|c|}
\hline Variable & $\begin{array}{l}\text { Received } \\
\text { second dose }\end{array}$ & $\begin{array}{l}\text { Did not receive } \\
\text { second dose }\end{array}$ & Relative risk ${ }^{\star}$ & $\begin{array}{l}95 \% \\
\text { Confidence } \\
\text { interval }\end{array}$ & p Value \\
\hline $\begin{array}{l}\text { Parents' mean (SD) monthly income } \\
\quad(\text { taka†) }\end{array}$ & $\begin{array}{l}3752(2700) \\
\text { Living condit }\end{array}$ & $\begin{array}{c}1976(1472) \\
\text { ions (economic ind }\end{array}$ & dicators) & 94 to $2558 \ddagger$ & $<0.004$ \\
\hline $\begin{array}{l}\text { No of rooms: } \\
\quad \leqslant 1 \\
>1\end{array}$ & $\begin{array}{l}29 \\
17\end{array}$ & $\begin{array}{r}60 \\
7\end{array}$ & $\begin{array}{c}2 \cdot 31 \\
\mathrm{RC}\end{array}$ & 1.22 to 4.38 & $<0.001$ \\
\hline $\begin{array}{l}\text { No of beds: } \\
\leqslant 1 \\
>1\end{array}$ & $\begin{array}{l}30 \\
16\end{array}$ & $\begin{array}{r}60 \\
7\end{array}$ & $2 \cdot 19$ & $1 \cdot 16$ to $4 \cdot 13$ & $<0.002$ \\
\hline $\begin{array}{l}\text { Cement floor: } \\
\text { No } \\
\text { Yes }\end{array}$ & $\begin{array}{l}19 \\
27\end{array}$ & $\begin{array}{l}53 \\
14\end{array}$ & $2 \cdot 16$ & 1.38 to 3.37 & $<0.001$ \\
\hline $\begin{array}{l}\text { Cement roof: } \\
\text { No } \\
\text { Yes }\end{array}$ & $\begin{array}{l}26 \\
20\end{array}$ & $\begin{array}{r}60 \\
7\end{array}$ & $\begin{array}{l}2 \cdot 69 \\
\mathrm{RC}\end{array}$ & 1.40 to $5 \cdot 17$ & $<0.001$ \\
\hline $\begin{array}{l}\text { Owns fan: } \\
\text { No } \\
\text { Yes }\end{array}$ & $\begin{array}{l}18 \\
28\end{array}$ & $\begin{array}{r}58 \\
9\end{array}$ & $\begin{array}{l}3 \cdot 14 \\
\mathrm{RC}\end{array}$ & 1.75 to 5.61 & $<0.001$ \\
\hline $\begin{array}{l}\text { Owns radio: } \\
\text { No } \\
\text { Yes }\end{array}$ & $\begin{array}{l}23 \\
23\end{array}$ & $\begin{array}{l}54 \\
13\end{array}$ & $\begin{array}{l}1.94 \\
\mathrm{RC}\end{array}$ & 1.23 to 3.07 & $<0.001$ \\
\hline $\begin{array}{l}\text { Owns television: } \\
\text { No } \\
\text { Yes }\end{array}$ & $\begin{array}{l}29 \\
17\end{array}$ & $\begin{array}{r}64 \\
3\end{array}$ & $\begin{array}{l}4.59 \\
\mathrm{RC}\end{array}$ & 1.60 to 13.14 & $<0.001$ \\
\hline $\begin{array}{l}\text { Uses gas for cooking: } \\
\text { No } \\
\text { Yes }\end{array}$ & $\begin{array}{l}21 \\
25\end{array}$ & $\begin{array}{l}50 \\
17\end{array}$ & $\begin{array}{l}1.74 \\
\mathrm{RC}\end{array}$ & 1.17 to 2.59 & $<0.002$ \\
\hline $\begin{array}{l}\text { Source of water for washing/bathing: } \\
\text { Surface water } \\
\text { Other (safe water) }\end{array}$ & $\begin{array}{r}5 \\
41\end{array}$ & $\begin{array}{l}24 \\
43\end{array}$ & $\begin{array}{ll}1.62 \\
\mathrm{RC}\end{array}$ & $1 \cdot 24$ to $2 \cdot 11$ & $<0.005$ \\
\hline
\end{tabular}

and sanitation which may indicate general environmental health are shown in table I.

\section{ANALYSIS OF GROUPS GIVEN AND NOT GIVEN SECOND} DOSE

Forty six of the 113 children received their second dose of diphtheria, tetanus, and pertussis vaccine. The two most significant characteristics that distinguished these children from the remainder were parents' education and economic status. Birth order and nutritional status also varied between the groups.

Economic status was estimated from the possession of goods and services, the type of house, and the size of income (table I). Income was $\mathbf{9 0 \%}$ higher among families whose children received the second dose of vaccine. Univariate analysis showed that a significantly higher proportion of families in this group had more than one room and one bed, a cement floor, and a cement block roof and owned a radio, fan, and television. Poor economic conditions as reflected by lack of goods and services as well as by poorer housing were associated with a twofold to threefold increase in the risk of non-compliance with the second dose (table I). Families of children who received the second dose tended to have lived longer in their accommodation (45 months as opposed to 34) and to lead more secure and settled lives. When we considered all the economic indicators as a composite there was a clear correlation between economic status and compliance with the second dose.

Education-There was a high degree of correlation between mothers' education and whether children had their second dose of the vaccine. Mothers of children who received the second dose had had a mean of four years' schooling, and mothers of children who did not receive the second dose had had a mean of one year's schooling. Whereas only $14(30 \%)$ mothers in the group given the second dose had had no schooling 45 $(67 \%)$ mothers in the group not given the second dose had had no schooling. Children of women who had not been to school were nearly twice as likely not to have their second dose of vaccine as children of mothers who had been to school. Fathers of children who received the second dose had also had more schooling (mean seven years) than fathers in the other group (mean three years) (table II).

Knowledge and motivation-In the first interview parents were asked about the purpose of vaccination, whether they could name any of the diseases it protects against, and how many doses were required. Those whose children received the second dose of the vaccine were more than twice as likely to know that three or four visits to the immunisation centre are required (table II). Were some more able to retain and understand what they had been told because of their education or did staff explain things better to the educated ones because of their perceived status? This is an important area for further research as preferential treatment by health care providers has been documented elsewhere. ${ }^{4}$ What is clear is that children whose parents were not able to answer knowledgeably in the first interview were also less likely to have their second dose.

Satisfaction with curative treatment-Paradoxically, table III shows that parents of children who did not have their second dose of the vaccine expressed higher levels of satisfaction with hospital care than did parents of children in the other group. The difference, however, was not significant.

Nutrition-Mean weight for age (expressed as percentage of National Center for Health Statistics median) and mean mid-arm circumference were significantly greater in children who received the second dose of the vaccine $(p=0.03)$. This may simply reflect their better economic status or possibly regardless of 
TABLE II-Education and knowledge associated with non-compliance with second dose of diphtheria, tetanus, and pertussis vaccine and their relative risks. Figures are numbers (and numbers (percentages)) of families of children who did or did not receive second dose of vaccine

\begin{tabular}{|c|c|c|c|c|c|}
\hline Variable & $\begin{array}{l}\text { Received } \\
\text { second dose }\end{array}$ & $\begin{array}{l}\text { Did not receive } \\
\text { second dose }\end{array}$ & $\begin{array}{c}\text { Relative } \\
\text { risk }^{\star}\end{array}$ & $\begin{array}{c}95 \% \\
\text { Confidence } \\
\text { interval }\end{array}$ & $\mathrm{p}$ Value \\
\hline \multicolumn{6}{|c|}{ Education of parents } \\
\hline \multicolumn{6}{|l|}{ Mother's education: } \\
\hline No schooling & 14 & 45 & 1.87 & $1 \cdot 32$ to $2 \cdot 66$ & $<0 \cdot 001$ \\
\hline$\geqslant 1$ Year of schooling & 32 & 22 & $\mathrm{RC} t$ & & \\
\hline \multicolumn{6}{|l|}{ Father's education: } \\
\hline No schooling & 10 & 36 & $2 \cdot 7$ & 1.52 to 4.77 & $<0.001$ \\
\hline $1-10$ Years of schooling & 14 & 22 & $2 \cdot 1$ & $1 \cdot 14$ to $3 \cdot 87$ & $<0 \cdot 01$ \\
\hline$>10$ Years of schooling & 22 & 9 & $\mathrm{RC}$ & & \\
\hline \multicolumn{6}{|c|}{ Knowledge about immunisation } \\
\hline \multicolumn{6}{|c|}{ No of times child should be vaccinated: } \\
\hline Do not know & 15 & 43 & 1.79 & $1 \cdot 23$ to $2 \cdot 62$ & $<0.001$ \\
\hline Once or twice & 4 & 5 & $1 \cdot 35$ & 0.68 to 2.65 & $0 \cdot 48$ \\
\hline Three or four times & 27 & 19 & $\mathrm{RC}$ & & \\
\hline \multicolumn{6}{|c|}{ Response to question "Name diseases immunisation protects against" $\ddagger$} \\
\hline Tetanus & $40(87)$ & $40(60)$ & $1 \cdot 64$ & $1 \cdot 25$ to $2 \cdot 15$ & $<0.002$ \\
\hline Diphtheria & $34(74)$ & $30(45)$ & 1.61 & $1 \cdot 19$ to $2 \cdot 14$ & $<0.005$ \\
\hline Pertussis & $29(63)$ & $28(42)$ & 1.42 & 1.03 to 1.94 & 0.027 \\
\hline Measles & $32(70)$ & $21(31)$ & 1.93 & 1.35 to 2.77 & $<0.001$ \\
\hline Poliomyelitis & $16(35)$ & $21(31)$ & 1.07 & 0.76 to 1.49 & 0.703 \\
\hline Tuberculosis & $27(59)$ & $33(49)$ & $1 \cdot 17$ & 0.86 to 1.58 & 0.325 \\
\hline
\end{tabular}

^Relative risk was calculated to ascertain whether factor was more likely to be associated with child not receiving second dose of vaccine.

tRC=Referenceicategory

$\ddagger$ Inability to name diseases was factor with respect to which relative risk was calculated for non-compliance with second dose of vaccine.

TABLE III-Other factors associated with non-compliance with second dose of diphtheria, tetanus, and pertussis vaccine and their relative risks. Except where stated otherwise, figures are numbers of families of children who did or did not receive second dose of vaccine

\begin{tabular}{|c|c|c|c|c|c|}
\hline Variable & $\begin{array}{l}\text { Received } \\
\text { second dose }\end{array}$ & $\begin{array}{l}\text { Did not receive } \\
\text { second dose }\end{array}$ & $\begin{array}{c}\text { Relative } \\
\text { risk }^{\star}\end{array}$ & $\begin{array}{c}95 \% \\
\text { Confidence } \\
\text { interval }\end{array}$ & p Value \\
\hline \multicolumn{6}{|l|}{ Mean (SD) duration of stay in } \\
\hline Fully satisfied with hospital care: & & & & & \\
\hline $\begin{array}{l}\text { No } \\
\text { Yes }\end{array}$ & 16 & $\begin{array}{l}18 \\
44\end{array}$ & $0 \cdot 89$ & 0.62 to 1.29 & 0.526 \\
\hline \multicolumn{6}{|l|}{ Mean (SD) weight for age } \\
\hline ( $\%$ of NCHS median) $\uparrow$ & $77 \cdot 1(11 \cdot 4)$ & $72 \cdot 5(10 \cdot 6)$ & & 0.45 to $8.75 t$ & 0.031 \\
\hline $\begin{array}{l}\text { Mean }(\mathrm{SD}) \text { mid-arm } \\
\text { circumference }(\mathrm{mm})\end{array}$ & $117 \cdot 6(12 \cdot 7)$ & $112 \cdot 5(11 \cdot 0)$ & & 0.65 to $9.55 \dagger$ & 0.030 \\
\hline \multicolumn{6}{|l|}{ Breast fed: } \\
\hline No & 5 & 4 & 0.73 & 0.35 to 1.55 & $0 \cdot 347$ \\
\hline Yes & 41 & 63 & $\mathrm{RC}$ & & \\
\hline \multicolumn{6}{|l|}{ Uses bottle feed: } \\
\hline Yes & 17 & 28 & $1 \cdot 08$ & 0.80 to 1.47 & $0 \cdot 608$ \\
\hline No & 29 & 39 & $\mathrm{RC}$ & & \\
\hline \multicolumn{6}{|l|}{ Sex: } \\
\hline Female & 18 & 28 & 1.05 & 0.77 to 1.42 & $0 \cdot 778$ \\
\hline Male & 28 & 39 & $\mathrm{RC}$ & & \\
\hline \multicolumn{6}{|l|}{ Birth order: } \\
\hline $3 r d$ & 19 & 34 & 1.01 & 0.74 to 1.38 & 0.942 \\
\hline 2nd & 12 & 7 & 0.58 & 0.31 to 1.09 & 0.056 \\
\hline $1 \mathrm{st}$ & 15 & 26 & $\mathrm{RC}$ & & \\
\hline Mean (SD) age of child (months) & $8 \cdot 6(4 \cdot 7)$ & $8 \cdot 9(4 \cdot 7)$ & & & 0.79 \\
\hline Mean (SD) age of father (years) & $30 \cdot 2(4 \cdot 4)$ & $33 \cdot 4(12 \cdot 7)$ & & & $0 \cdot 105$ \\
\hline Mean (SD) age of mother (years) & $23 \cdot 7(4 \cdot 3)$ & $23 \cdot 9(4 \cdot 4)$ & & & $0 \cdot 786$ \\
\hline
\end{tabular}

^Relative risk was calculated to ascertain whether factor was more likely to be associated with child not receiving second dose of vaccine.

$95 \%$ Confidence interval fo

difference between means.

difference betu

$\ddagger R a n k$ test.
$\bigcap R C=$ Reference category.

INCHS = National Center for Health Statistics.

economic status children who are perceived to be unwell are less likely to be taken for vaccination (table III).

Gender-Although boys were more likely to be admitted to hospital for curative treatment than girls, gender did not seem to be relevant in determining whether a child received the second dose of the vaccine; 28 of the 67 boys $(42 \%)$ and 18 of the 46 girls (39\%) were given the second dose.

Birth order-Among the children who received the second dose of the vaccine nine $(32 \%)$ of the boys and six $(33 \%)$ of the girls were firstborn. As place in the birth order increased, however, the percentage of girls decreased, suggesting that girls in particular who are not first or second born are less likely to be brought back.

\section{Discussion}

The WHO progress and evaluation report ${ }^{1}$ refers to the opportunities missed if health centres do not offer immunisation. The challenge, therefore, is not only to give the first dose to the unimmunised child but to motivate parents to complete the course. What factors determine whether those who receive the first dose in a hospital will return for subsequent doses after discharge? Our study shows that children who were brought back for their second dose of vaccine came from households with a significantly higher socioeconomic status. The other significant characteristic that differentiated them was parental education, particularly mothers' education. Mother's education has been shown to have a strong statistical association with child survival. ${ }^{56}$ Immunisation may be one pathway linking these two variables. Mother's education and socioeconomic status seem to be closely associated covariates.

Our findings suggest that motivational effort should be directed at poorer and less educated parents. Furthermore, health education and information from the WHO expanded programme on immunisation must be targeted at and designed for those who are non-literate and do not own televisions or radios. This is consistent with other Bangladeshi studies which showed that most parents recalled the campaign logo of the expanded programme on immunisation and were motivated by contact with a health worker rather than by television or radio. ${ }^{47}$

We found a significant difference in level of knowledge about the expanded programme on immunisation between the two groups, which suggests that giving information and education is an essential part of the motivational process. Paradoxically, parents who brought their children back for the second dose of the vaccine were less likely to be satisfied with the hospital care that the children had received. This has positive implications in relation to the WHO policy on missed opportunities for immunisation in hospitals. It suggests that negative experiences in a curative context do not necessarily prevent parents from bringing children back for their second dose of vaccine. On the contrary, children whose parents were critical about treatment were more likely to complete the full immunisation course. A hospital stay is not only a chance to give the first dose of vaccine but it is also the opportunity to give health education that will effectively motivate parents in the future. This has policy implications for other areas of primary health care and suggests that health education is appropriate in a treatment setting.

The relation between mothers' education and child survival has been well documented. ${ }^{56}$ What is less well understood is the nature of this relation. Our findings suggest one explanation, which is that schooling makes women better able to understand and use preventive health care facilities such as immunisation. A further question calling for qualitative research is the extent to which health education strategies could be better designed to meet the needs of those who have not been to school. We have raised the issue of staff perceptions and the possibility that education may act as a proxy for higher status, which causes health workers to treat educated parents differently. This is a fruitful topic for operational research. The WHO predicts that the expanded programme on immunisation will increasingly promote other primary health care practices which are consistent with its delivery system and target populations.' Our study shows how health workers can promote immunisation in a curative context as an integrated part of primary health care in Bangladesh.

This study was supported by the Danish International Development Agency (DANIDA) and the International Centre for Diarrhoeal Disease Research, Bangladesh (ICDDR,B). The ICDDR,B is supported by countries and agencies which share its concern for the health problems of 
developing countries. Current donors include Australia, Bangladesh, Belgium, Canada, France, Japan, the Netherlands, Norway, Switzerland, the United Kingdom, and the United States; international organisations including the United Nations Children's Fund, United Nations Capital Development Fund, and the World Health Organisation; and private foundations including the Ford Foundation and Sasakawa Foundation.

We acknowledge the help of all the immunisation workers of the child health programme of the ICDDR,B, and the WHO expanded programme on immunisation, and the patients who gave us their time and cooperation. We also acknowledge the expanded programme on immunisation for the necessary logistics for immunisation. We are grateful to Mr M A Hasnat for his assistance with data analysis, Mr A R Patwary for invaluable help, and Dr Mridul K Chowdhury for his comments. We also express our sincere thanks to
Drs A K Mitra, R Bairagi, and K Stewart for reviewing the manuscript.

1 World Health Organisation. Expanded programme on immunization: progress and evaluation report. Geneva: WHO, 1989. (A42/10.)

2 Unicef. The state of the world's children. Oxford: Oxford University Press, 1991:102-3.

3 Greenland S, Robins JM. Estimation of a common effect parameter from sparse follow-up data. Biometrics 1985;41:55-68.

4 Schuler SR. Barriers to effective family planning in Nepal. Stud Fam Plann 1985;16:260-70.

5 Caldwell J. Routes to low mortality in poor countries. Population Developmen Review 1986;12:171-220.

6 Bairagi R. Is income the only constraint on child nutrition in rural Bangladesh? Bull World Health Organ 1988;58:767-72.

7 Gupta AD. Communicating immunization: a study of community attitudes and responses to immunization in Bangladesh. Dhaka: Worldwide International Foundation, 1988

(Accepted 30 October 1991$)$

\title{
Physiotherapy intervention late after stroke and mobility
}

\author{
Derick T Wade, Fiona M Collen, Gillian F Robb, Charles P Warlow
}

\begin{abstract}
Objective-To determine whether the intervention of a physiotherapist improved mobility in patients seen more than one year after stroke.

Design-Randomised crossover trial comparing two groups offered intervention by a physiotherapist, one immediately after entry into the trial and the other after a delay of three months. The intervention consisted of identifying problems and offering advice and help to solve the problems.

Setting-Patients' homes in Oxfordshire.

Subjects-Patients who had reduced mobility due to a stroke more than one year before entry; 60 were recruited from a community stroke register and 34 in other ways.
\end{abstract}

Main outcome measures-Standard measures of mobility including gait speed, functional ambulation categories, the Nottingham extended activities of daily living index, and individual items from the Barthel activities of daily living index and the Frenchay activities index. Measures of manual dexterity, depression, and anxiety were used as controls.

Results -94 patients entered the trial and 49 were randomised to immediate and 45 to delayed physiotherapy; 89 were compared at the crossover point. At randomisation the two groups were comparable. At three months the group given early therapy showed an improvement in gait speed whereas the untreated group had declined (differences of $-3.9 v$ $6.4 \mathrm{~s}$ to walk $10 \mathrm{~m} ; \mathrm{p}<0.01$ ); between three and six months the group given delayed therapy showed improvement and the previously treated group declined (differences of $6.5 v-3.9 \mathrm{~s}$ to walk $10 \mathrm{~m}$; $\mathrm{p}<0.01)$. A $9 \%(95 \%$ confidence interval $0 \%$ to $18 \%)$ decrease in time taken to walk $10 \mathrm{~m}$ was associated with treatment and a $12 \%(2 \%$ to $19 \%)$ increase when patients were untreated. Other measures did not change significantly.

Conclusion-Intervention of an experienced physiotherapist late after stroke specifically improves mobility, albeit by a small amount, but the effects do not seem to be maintained, perhaps because there is an underlying decline in mobility in these patients. Gait speed offers a simple and sensitive measure of outcome.

\section{Introduction}

Over half of all stroke survivors have continuing problems with mobility, '2 although not all these prob- lems arise from the stroke. Many doctors and patients think that physiotherapy may help. Some studies suggest that late rehabilitation might lead to considerable general benefit ${ }^{3+}$ but there is little specific evidence to guide doctors, therapists, or managers when considering physiotherapy after stroke. Further, none of the few randomised studies on rehabilitation after stroke have specifically investigated the effect on mobility. Some small studies have investigated the effects on mobility of particular interventions such as the use of foot splints or biofeedback. ${ }^{56}$

The Oxfordshire community stroke project's register of long term stroke survivors ${ }^{7}$ allowed us to study the effects on mobility of physiotherapy given to patients who would not be expected to show much spontaneous change and yet for whom physiotherapy is often suggested. We investigated the effects on patients' mobility of being seen, advised, and sometimes treated by a physiotherapist late after stroke. The primary aim was to detect whether mobility improved as a result of the intervention. The design incorporated a control group given therapy after a delay, and a modified crossover analysis was also undertaken.

\section{Method}

All patients studied had mobility problems more than one year after stroke: they used a walking or mobility aid, other than just a stick; had had a fall in the previous three months; were unable to manage stairs, slopes, or uneven surfaces independently; or had a slow gait speed $>10 \mathrm{~s}$ over $10 \mathrm{~m}$ if under $60,>12 \cdot 5 \mathrm{~s}$ if $60-69,>16 \cdot 5 \mathrm{~s}$ if over $70 .^{2}$ Patients who had agreed to enter the trial were accepted unless we were unable to detect an impairment related to stroke that was likely to reduce mobility and also able to identify an alternative cause for impaired mobility.

Most patients $(n=60)$ were recruited from the 328 survivors in the Oxfordshire community stroke project. ${ }^{78}$ At final follow up two to seven years after their first stroke patients were assessed for mobility and, if eligible, they were asked to enter the study. Those accepting were contacted six to 12 months later and assessed by a non-treating physiotherapist who decided whether the mobility problems were due to stroke; if so the patient was entered into the trial.

Calculations based on published evidence ${ }^{129}$ sug gested that a sample of 100 patients would give an $80 \%$ chance at the $5 \%$ level of detecting a one category improvement - for example, in walking outdoors - in $10 \%$ of patients. We expected to recruit this number
Correspondence to:

B.MF 1992:304:609-13 